\title{
Using the Graf method of ultrasound examination to classify hip dysplasia in neonates
}

\author{
Bruno de Castro Paixão Jacobinoa, Mariana Domingues Galvãoa, \\ Adriano Ferreira da Silva ${ }^{b}$, Cláudio Campi de Castro ${ }^{\mathrm{b}, \mathrm{c}}$
}

Jacobino BCP, Galvão MD, Silva AF, Castro CC. Using the Graf method of ultrasound examination to classify hip dysplasia in neonates. Autopsy Case Rep [Internet]. 2012;2(2):5-10. http://dx.doi.org/10.4322/acr.2012.018

\section{ABSTRACT}

Developmental dysplasia of the hip (DDH) is one of the most common congenital orthopedic anomalies. Ultrasound examination employing the Graf method is used to diagnose DDH. We conducted a retrospective cross-sectional study of 222 neonatal patients (140 females and 82 males) submitted to ultrasound examination of the right and left hips between January of 2009 and May of 2011. The mean age was 5.0 days. The patients were grouped by laterality, mean alpha $(\alpha)$ and beta $(\beta)$ angles (in degrees), and hip type (as determined by the Graf classification). The data collected were statistically correlated. Mean $\alpha$ angle values were higher in males than in females, as well as being higher for right hips than for left hips $(p<0.001)$. In contrast, mean $\beta$ angle values were lower in males than in females, as well as being lower for right hips than for left hips ( $p<0.001)$. Type la hips (i.e., mature hips) predominated in both genders and on both sides, having been found in $82.32 \%$ of the examinations of males and in $71.09 \%$ of those of females. The right hip was classified as type la in $78.38 \%$ of the examinations, and the left hip was classified as type la in $72.07 \%$. Type lla hips (i.e., immature hips) were found in $12.8 \%$ of the examinations of males and in $20 \%$ of those of females. The right hip was classified as type Ila in $13.96 \%$ of the examinations, and the left hip was classified as type Ila in $20.72 \%$. The remaining hip types were less common. We emphasize the importance of ultrasound as a standard method of screening for DDH.

Keywords: Hip Dislocation; Ultrasonography; Congenital Abnormalities; Infant; Newborn.

\section{INTRODUCTION}

The term congenital dislocation of the hip has traditionally been used in order to describe infant hip abnormalities that can progress to dislocation. Developmental dysplasia of the hip (DDH) is currently the preferred term and denotes the same range of hip problems but also includes hips that have not been classified as dislocated but are poorly developed, as well as hips that are determined to be abnormal after the neonatal period. ${ }^{1}$ Although the new term has been adopted by the American Academy of Pediatrics, the American Academy of Orthopedic Surgeons, and the Pediatric Orthopedic

\footnotetext{
a Institut of Heart - Faculdade de Medicina - Universidade de São Paulo, São Paulo/SP - Brazil.

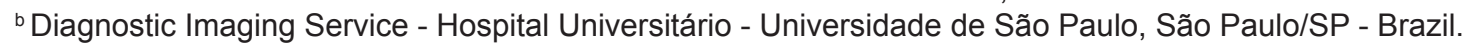

${ }^{\mathrm{C}}$ Department of Radiology - Faculdade de Medicina - Universidade de São Paulo, São Paulo/SP - Brazil.
}

Copyright $\odot 2012$ Autopsy and Case Reports - This is an Open Access article distributed of terms of the Creative Commons Attribution NonCommercial License (http://creativecommons.org/licenses/by/3.0/) which permits unrestricted non-commercial use, distribution, and reproduction in any médium provided article is properly cited. 
Society of North America, it has yet to be universally employed. ${ }^{1}$

In 1927, Hey-Groves defined DDH as a disease that is silent, painless, and difficult to diagnose, and that inevitably has disastrous consequences if it is not treated in a timely manner. ${ }^{1}$ In cases of subluxation of the hip, the femoral head is displaced from its normal anatomical position but still maintains some contact with the acetabular cavity. In cases of hip dislocation, there is no contact between the femoral head and the acetabular cavity. An unstable hip is the one reduced in the acetabulum but can be provoked to subluxate or dislocate. $^{2}$

The incidence of DDH is variable and depends on many factors, including geographic region of birth/genetics; for instance, the incidence of DDH is higher among Italians and those of Italian descent (including those who emigrate to other geographic regions). ${ }^{3}$ It has been estimated that approximately 1 in every 1,000 neonates is born with hip dislocation, and that approximately 10 in every 1,000 neonates are born with hip subluxation (unstable hip). ${ }^{3}$

The neonatal risk factors for DDH include being female; being White; having a primiparous young mother; having been a breech presentation; having suffered from oligohydramnios; having a family history of $\mathrm{DDH}$; being above average in terms of weight and length; and having foot or spinal column deformities. ${ }^{3,4}$ One of the most common congenital orthopedic anomalies, DDH can lead to changes of a disabling nature, hence the need for early diagnosis and treatment (on the first day of life, if possible). ${ }^{2}$

Regarding the clinical diagnosis of $\mathrm{DDH}$, there is no consensus in the literature regarding the best DDH evaluation protocol. The Ortolani and Barlow tests are the standard techniques for the detection of hip instability in neonates. ${ }^{1-4}$ The efficacy of those tests is variable, due to the experience of the examining doctor. ${ }^{4}$ In order to perform theses maneuvers, the hips of the infant are flexed to $90^{\circ}$, the thumbs of the examiner are placed on the medial proximal thigh, and the fingers are placed over the greater trochanter. In the Ortolani test, the contralateral hip is held still while the thigh being tested is abducted and gently pulled anteriorly. The sensation of instability in a positive Ortolani test is the palpable and sometimes audible "clunk" of the femoral head moving over the posterior rim of the acetabulum and relocating in the cavity. ${ }^{1-4}$

The Barlow test is a maneuver in which the examiner attempts to dislocate the unstable hip. The thighs of the patient are held at a right angle to the trunk, in an adduction position; the knee of the child will exert force in a vertical direction to the hip, in an effort to dislocate the femoral head from within the acetabulum. The examiner looks for laxity in the hip being examined, a sign that may or may not be accompanied by a "clunk". The top of the femur is held between the index and middle fingers and over the greater trochanter, and the thumb is placed on the groin. The femoral head can be levered into and out of the joint, confirming the instability of the hip. ${ }^{1-4}$

Since the publication of an early study conducted by Graf, ${ }^{5}$ ultrasound of the hip has gained wide acceptance as the primary method of screening for, diagnosing, and monitoring the treatment of $\mathrm{DDH}$ in infants. At facilities in Brazil, the static ultrasound examination introduced by Graf in 1980 and the dynamic ultrasound examination recommended by Harcke et al. in 1985 continue to be the most widely used methods. ${ }^{1,2}$ In addition to being fast and completely innocuous, ultrasound examination requires no contrast agents nor anesthesia. ${ }^{2}$ For static ultrasound examination, the patient is placed in the lateral decubitus position with the hips slightly flexed, adducted, and medially rotated (Figure 1), and a coronal sonogram is obtained with a highresolution $\left(5-\right.$ to $10 \mathrm{MHz}$ ) linear transducer. ${ }^{4}$

In the Graf method, the hip is evaluated by measuring two angles formed by three lines drawn

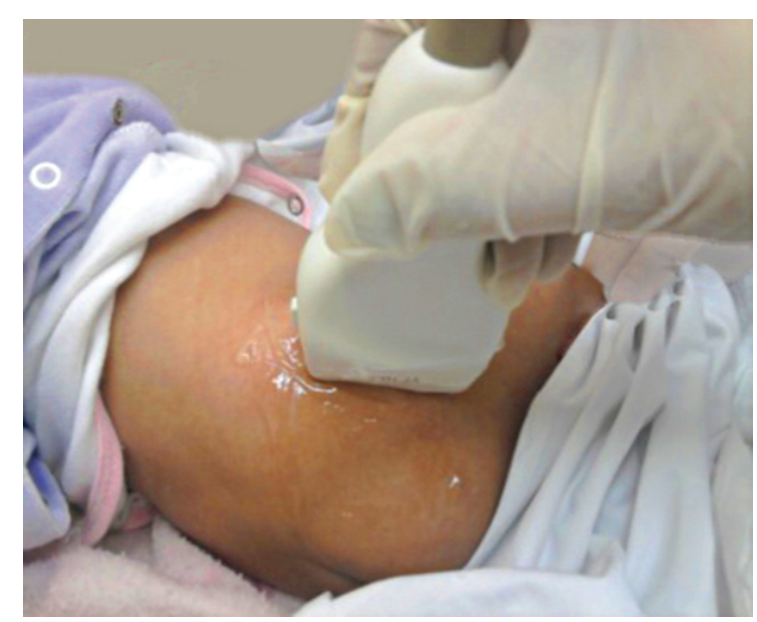

Figure 1 - Patient positioning for ultrasound examination of the hip. The patient is placed in the lateral decubitus position with the hips slightly flexed, adducted, and medially rotated. 
from three landmarks, namely the lateral edge of the acetabulum, the bottom of the acetabulum, and the acetabular labrum. These three lines are: the bony roof line, the baseline, and the cartilage roof line measured at the acetabular labrum (Figure 2). After these lines have been drawn, the bony roof angle (known as the alpha [a] angle) and the cartilage roof angle (known as the beta $[\beta]$ angle) are determined (Figure 3). $\cdot^{2-4}$

The Graf classification is shown in Table 1. The $\alpha$ and $\beta$ angle values are correlated with a scale of severity4:

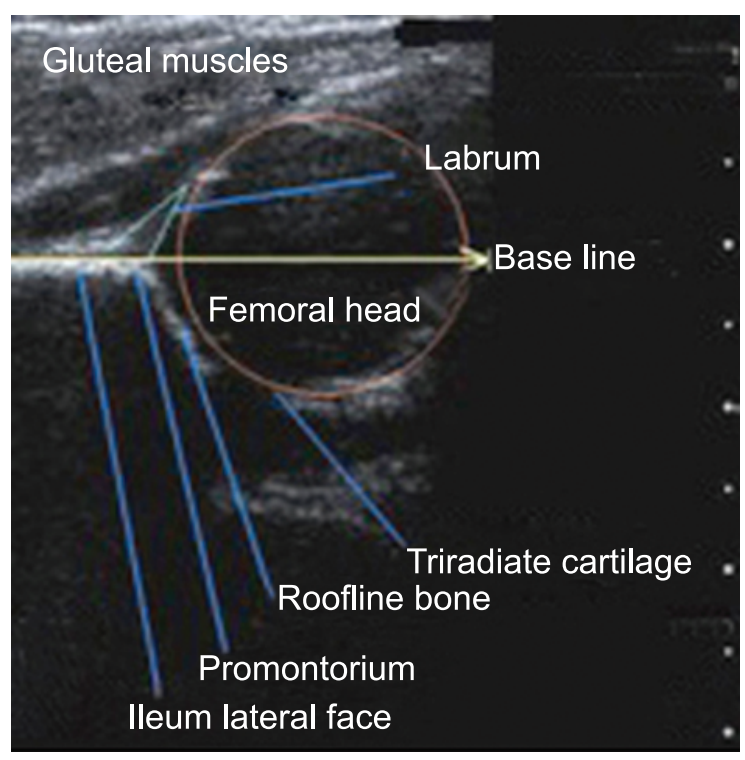

Figure 2 - Infant hip joint components as seen on ultrasound examination.

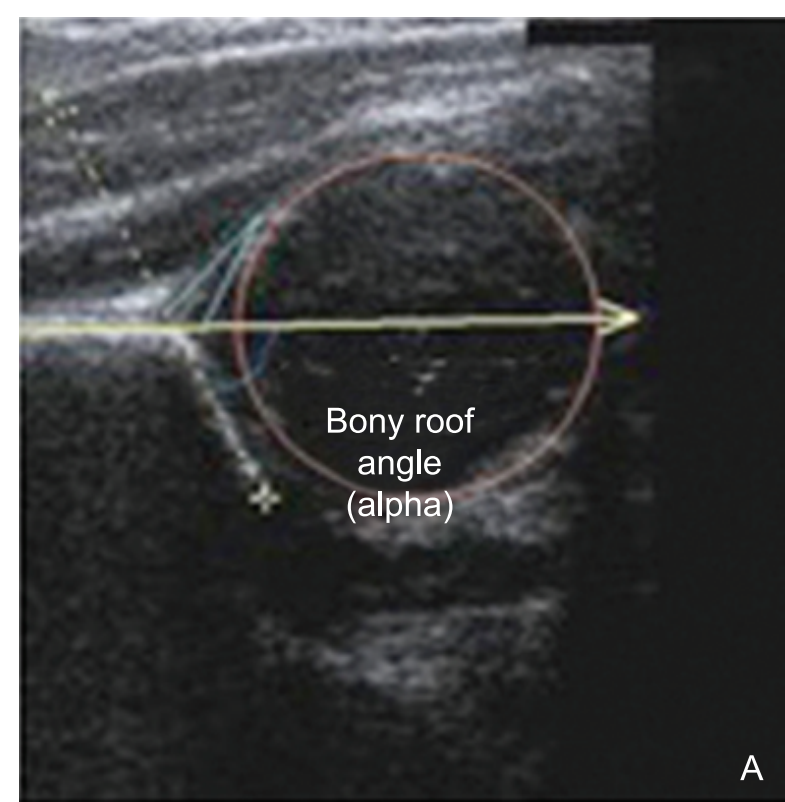

- Type la and lb hips are mature hips;

- Type Ila hips are immature hips;

- Type Ilb and Ilc hips are dysplastic hips;

- Type IIla and IIlb hips are subluxated; and

- Type IV hips are dislocated.

The treatment of DDH depends on the age of the child ${ }^{4}$ :

- Children aged $\leq 6$ months are placed in a Pavlik harness, which maintains the hips flexed and abducted;

- Children aged 6-18 months undergo closed reduction and spica casting; and

- Children aged >18 months undergo open reduction and spica casting.

The objective of this article was to draw a profile of the incidence of the various Graf hip types on the basis of the ultrasound examinations, as well as to correlate that incidence with age; gender; laterality; the $\alpha$ and $\beta$ angles; and the Graf classification.

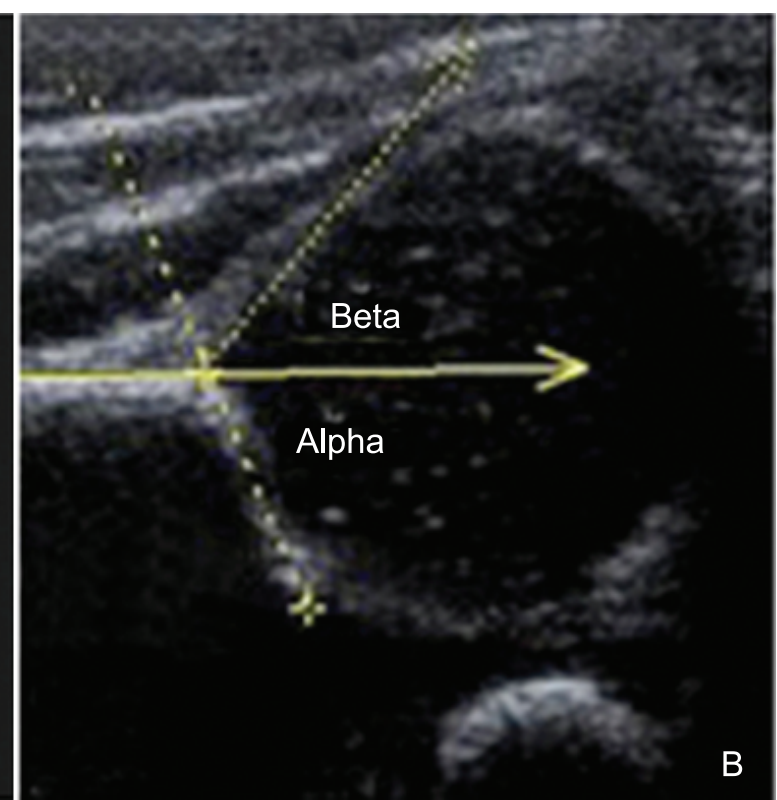

Figure 3 - A - Measurement of the bony roof angle ( $\alpha$ angle); B - Measurement of the cartilage roof angle ( $\beta$ angle). 


\section{METHODS}

We conducted a qualitative, retrospective cross-sectional study by reviewing the medical records of 222 children who were born at or admitted to the University of São Paulo University Hospital and who underwent ultrasound examination of the right and left hips (initial examination) in the Department of Diagnostic Imaging between January of 2009 and May of 2011. The patients were stratified by gender, as well as by age ( $<1$ month of age; $1-3$ months of age; and $>3$ months of age).

We collected the mean values of the $\alpha$ and $\beta$ angles (in degrees), as well as the hip types, i.e., Ia, Ib, IIa, IIb, IIc, IId, IIIa, IIIb, and IV, as determined by the Graf classification. The data collected were statistically correlated by the paired t-test, Pearson's correlation test, and the nonparametric Mann-Whitney test.

\section{RESULTS}

Of the 222 patients evaluated, 140 were female and 82 were male. The mean age was 5.0 days. In the female patients, the mean $\alpha$ angles were $60.7 \pm 4.96^{\circ}$ for the right hip and $60.2 \pm 4.58^{\circ}$ for the left (Figure 4), whereas the mean $\beta$ angles were $51.2 \pm 6.13^{\circ}$ for the right hip and $52.03 \pm 5.97^{\circ}$ for the left (Figure 5).

In the male patients, the mean $\alpha$ angles were $63.1 \pm 3.77^{\circ}$ for the right hip and $62.5 \pm 4.07^{\circ}$ for the left (Figure 4), whereas the mean $\beta$ angles were $50.1 \pm 4.90^{\circ}$ for the right hip and $51.5 \pm 6.87^{\circ}$ for the left (Figure 5).

As shown in Table 2, type la hips predominated in both genders and on both sides, the right hip having been classified as type la in 174 examinations (78.38\%) and the left hip having been classified as type la in 160 (72.07\%). As shown in Table 3, type la hips were found in 135 (82.32\%) of the examinations of male patients and in 199 $(71.09 \%)$ of the examinations of female patients.

Type Ila hip was the second most common hip type, having been found in $21(12.8 \%)$ of the examinations of male patients and in $56(20 \%)$ of the examinations of female patients. As shown in Tables 2 and 3, the right hip was classified as type Ila in 31 examinations (13.96\%), compared with 46 examinations $(20.72 \%)$ for the left hip. The remaining hip types were less common (Tables 2 and 3). None of the patients under study presented with type IV hips.

Table 1 - Classification of developmental dysplasia of the hip according to Graf and modified by Sernik \& Cerri $^{4}$

\begin{tabular}{|c|c|c|c|c|}
\hline \multirow{2}{*}{ Type } & Bony roof & \multirow{2}{*}{ Promontorium } & Cartilaginous roof & \multirow{2}{*}{ Age } \\
\hline & $\alpha$ angle & & $\beta$ angle & \\
\hline \multirow{4}{*}{1} & & \multirow{4}{*}{ Angular or slightly rounded } & Extends to a greater distance & \multirow{4}{*}{ Any } \\
\hline & GO0d & & la $\left(\beta \leq 55^{\circ}\right)$ & \\
\hline & \multirow{2}{*}{$\geq 60^{\circ}$} & & Extends to a greater distance & \\
\hline & & & $\mathrm{lb}\left(\beta>55^{\circ}\right)$ & \\
\hline $\mathrm{Ila}+$ & $\begin{array}{c}\text { Adequate } \\
\alpha \text { between } 50-59^{\circ}\end{array}$ & Rounded & Covers the femoral head & $0-12$ weeks \\
\hline Ila- & $\begin{array}{c}\text { Deficient } \\
\alpha \text { between } 50-59^{\circ}\end{array}$ & Rounded & Covers the femoral head & $6-12$ weeks \\
\hline $\mathrm{Ilb}$ & $\begin{array}{c}\text { Deficient } \\
\alpha \text { between } 50-59^{\circ}\end{array}$ & Rounded & Covers the femoral head & $>12$ weeks \\
\hline Illc & $\begin{array}{c}\text { Highly deficient } \\
\alpha \text { between } 43-49^{\circ}\end{array}$ & Rounded to flat & Covers the femoral head $\beta \leq 77^{\circ}$ & Any \\
\hline Ild & $\begin{array}{c}\text { Highly deficient } \\
43-49^{\circ}\end{array}$ & Rounded to flat & Dislocated $\beta>77^{\circ}$ & Any \\
\hline Illa & Poor $\alpha<43^{\circ}$ & Flat & Shifted superiorly and normal echogenicity & Any \\
\hline IIlb & Poor $\alpha<43^{\circ}$ & Flat & Shifted superiorly and hyperechoic & Any \\
\hline IV & Poor $\alpha<43^{\circ}$ & Flat & Shifted inferiorly & Any \\
\hline
\end{tabular}




\section{DISCUSSION}

The analysis of the data collected revealed a predominance of type la hips (regardless of gender) in our study sample, a finding that is consistent with those reported in the literature. Baronciani et al. ${ }^{6}$ examined 3,509 patients and found type la right and left hips in $50.1 \%$; type Ila hips in $44.8 \%$; type Ilc hips or type Ild hips in 4.5\%; and type III or IV hips in $0.6 \%$. Gharedaghi et al. ${ }^{7}$ performed ultrasound examination of 288 neonates and found that 36

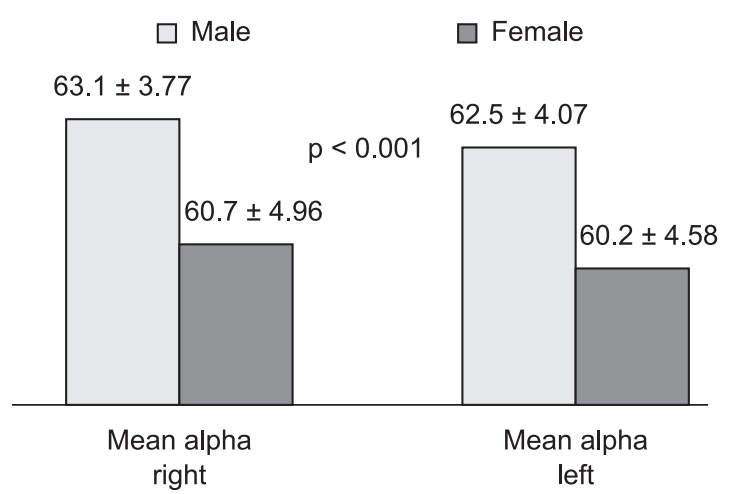

Figure 4 - Mean $\alpha$ angles by gender.

$\square$ Male

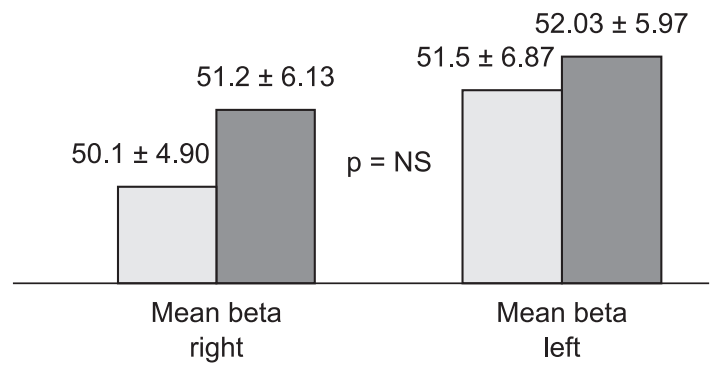

Figure 5 - Mean $\beta$ angles by gender. (NS, not significant).

Table 2 - Distribution of hip types (as determined by the Graf classification) by laterality

\begin{tabular}{cccccc}
\hline \multirow{2}{*}{$\begin{array}{c}\text { Graf hip } \\
\text { type }\end{array}$} & Right & Right & & Left & Left \\
\cline { 2 - 3 } \cline { 5 - 5 } & (n) & $(\%)$ & & (n) & (\%) \\
\hline Ia & 174 & 78.38 & & 160 & 72.07 \\
Ib & 12 & 5.41 & & 11 & 4.95 \\
Ila & 31 & 13.96 & 46 & 20.72 \\
Ilb & 2 & 0.90 & 2 & 0.90 \\
Ilc & 2 & 0.90 & 1 & 0.45 \\
IIla & 1 & 0.45 & 1 & 0.45 \\
IIlb & 0 & 0 & 1 & 0.45 \\
Total & 222 & 100 & 222 & 100 \\
\hline
\end{tabular}

$(12.5 \%)$ were suspected of having DDH; of those, $28(9.7 \%)$ were suspected of having type lla hips and $8(2.7 \%)$ were suspected of having type Ilb hips.

In the present study, $\alpha$ angle values were found to be higher in the male patients $(p<0.001$, as assessed by Pearson's correlation coefficient), a finding that is consistent with those reported in the literature. Sernik \& Cerri ${ }^{4}$ reported that the presence of relaxin (a hormone produced by the ovaries during pregnancy) constitutes a predisposing factor for $\mathrm{DDH}$, given that the hormone can cause capsular and ligamentous laxity, especially in female fetuses. In the present study, there were no statistically significant correlations between gender and mean $\beta$ angles.

Regarding laterality, $\alpha$ angle values were higher for the right hip, whereas $\beta$ angle values were lower ( $p<0.001$, as assessed by Pearson's correlation test). However, there were no statistically significant differences between sides in terms of the numbers of Graf's classification hips. Sernik \& Cerri ${ }^{4}$ reported that the incidence of DDH is up to 3 times as high in the left hip as it is in the right because the spinal column of the fetus is generally to the left of the mother in fetuses in cephalic presentation, which leads to limited abduction of the left hip.

One of the criticisms leveled at ultrasound is that it is operator-dependent and the interpretation of the same image by different examiners can lead to different approaches. Interobserver and intraobserver reliability has been widely studied, especially in terms of the Graf classification. According to Theis ${ }^{8}$, intraobserver reliability is good, whereas interobserver is only moderate.

Table 3 - Distribution of hip types (as determined by the Graf classification) by gender

\begin{tabular}{|c|c|c|c|c|}
\hline \multirow{3}{*}{$\begin{array}{l}\text { Graf hip } \\
\text { type }\end{array}$} & \multicolumn{4}{|c|}{ Gender } \\
\hline & \multicolumn{2}{|c|}{ Male } & \multicolumn{2}{|c|}{ Female } \\
\hline & (n) & $(\%)$ & (n) & (\%) \\
\hline la & 135 & 82.32 & 199 & 71.07 \\
\hline $\mathrm{lb}$ & 6 & 3.66 & 17 & 6.07 \\
\hline IIc & 21 & 12.80 & 56 & 20.00 \\
\hline Ilb & 1 & 0.61 & 3 & 1.07 \\
\hline IIc & 1 & 0.61 & 3 & 1.07 \\
\hline IIla & 0 & 0.00 & 2 & 0.71 \\
\hline IIIb & 0 & 0.00 & 0 & 0.00 \\
\hline TOTAL & 164 & 100.00 & 280 & 100.00 \\
\hline
\end{tabular}


Dias et al. ${ }^{9}$ showed that $\alpha$ and $\beta$ angle measurements are reasonably reproducible, while Cheng et al. ${ }^{10}$ found that the $\alpha$ angle was the most reliable measurement. ${ }^{9}$

In fact, in the literature, there is still no gold standard method for the evaluation of the infant hip. Because of its ease of use, ultrasound is the method that is most widely used for that purpose. However, to increase diagnostic accuracy, ultrasound findings should be correlated with clinical data.

\section{CONCLUSION}

Most of the ultrasound examinations reviewed in the present study revealed the presence of type I hips (i.e., mature hips). A diagnosis of $\mathrm{DDH}$ was found to be most common in females and in the left hip, which is in agreement with data in the literature. We emphasize the importance of performing ultrasound examination employing the Graf method, which represents the standard method of screening for DDH in neonates and infants, despite the low incidence of ultrasound examinations showing signs of positivity for $\mathrm{DDH}$. Data in the literature indicate that all neonates should undergo ultrasound examination as part of the screening for DDH. Unfortunatelly, not all hospitals are yet equipped to adopt this systematic approach. In order to evaluate the largest possible number of cases, ultrasound of the hip is currently performed in all neonates with risk factors for DDH and with clinical findings suggestive of such. Further prospective studies should compare the results of static ultrasound examination with those of dynamic ultrasound examination, especially in patients in whom static ultrasound examination is normal despite a high suspicion or a confirmed diagnosis of $\mathrm{DDH}$ (i.e., those already under treatment).

\section{REFERENCES}

1. French L, Dietz FR. Screening for developmental dysplasia of the hip. Am Fam Physician. 1999;60(1):187-8.

2. Milani C, Ishida A, Laredo Filho J, Kuwajima SS, Dodashi ET. Diagnóstico e tratamento da displasia do desenvolvimento do quadril. Diagn Tratamento. 2002;7(2):29-34. Portuguese.

3. Guarniero R. Displasia do desenvolvimento do quadril: uma atualização. Rev Bras Ortop. 2010;45(2):116-21. Portuguese. http://dx.doi.org/10.1590/S0102-36162010000200002

4. Sernik R, Ascencio JEB. Quadril. In: Cerri GG, Sernik R. Ultrassonografia do sistema musculoesquelético: correlação com ressonância magnética. Rio de Janeiro: Revinter; 2009. p. 259-315. Portuguese.

5. Graf R. The diagnosis of congenital hi-joint dislocation by the ultrasonic compound treatment. Arch Orthop Trauma Surg. 1980;97(2):117-33. http://dx.doi.org/10.1007/ BF00450934

6. Baronciani D, Atti G, Andiloro F, et al. Screening for developmental dysplasia of the hip: from theory to practice. Pediatrics. 1997;99(2):e5. PMid:9099762. http://dx.doi. org/10.1542/peds.99.2.e5

7. Gharedaghi M, Mohammadzadeh A, Zandi B. Comparison of clinical and sonographic prevalence of developmental dysplasia of the hip. Acta Med Iran. 2011;49(1):25-7. PMid:21425067.

8. Theis JC, Vane A. The role of ultrasound in developmental dysplasia of the hip. Indian J Orthop 2003;37(4):215-22.

9. Dias JJ, Thomas IH, Lamont AC, Mody BS, Thompson JR. The reliability of ultrasonographic assessment of neonatal hips. J Bone Joint Surg Br. 1993;75(3):479-82. PMid:8496227.

10. Cheng JCY, Chang YL, Hui PW, Metreweli C. Ultrasonographic hips morphometry in infants. J Pediatr Orthop. 1994;14(1):24-8. PMid:8113366. http://dx.doi. org/10.1097/01241398-199401000-00006

\section{Conflict of interest: None}

Submitted on: $16^{\text {th }}$ January 2012

Accept on: $15^{\text {th }}$ March 2012

Correspondence: Serviço de Iconologia

Av. Prof. Lineu Prestes, 2565 - Cidade Universitária - São Paulo/SP - Brazil

CEP: 05508-000 - Phone: +55 (11) 3091-9301

E-mail: adrimedsilva@uol.com.br 